\title{
ANALISIS KUALITAS PENGEMASAN VAKUM IKAN BEKU DENGAN METODE SIX SIGMA (Studi Kasus di PT X, Pasuruan Jawa Timur)
}

\author{
Sucipto Sucipto ${ }^{1,2^{*}}$, Retno Astuti ${ }^{1,2}$, Ayuningtyas Megawati ${ }^{1}$ \\ ${ }^{1}$ Program Studi Teknologi Industri Pertanian, Universitas Brawijaya \\ ${ }^{2}$ Halal-Qualified Industry Development (Hal-Q ID) Universitas Brawijaya, \\ Email: ciptotip@ub.ac.id
}

\begin{abstract}
Quality control is carried out as one of the strategies to measure the capability of the production process. This is to identify the factors that cause products no standardized and propose improvements. During this time, there are often problems in the vacuum packaging of frozen fish. The analysis method used Six Sigma with the stages Define, Measure, Analyze and Improve. The results showed that the Critical to Quality (CTQ) of packaging process is leaking packaging, but the process is working well and it is above the industry average in Indonesia. It can be seen the value of Sigma and the final yield. Packaging leaked based on a fishbone diagram and Failure Modes and Effects Analysis (FMEA) is caused by human factors.The proposed improvement is by monitoring, guidance, and training of human resources. This is done so that the process can be towards the target 6-Sigma
\end{abstract}

Keywords: FMEA, Six Sigma, Packaging, Vacuum, Fish

\section{PENDAHULUAN}

Kualitas ikan beku kemasan sangat ditentukan proses pengemasannya. PT X berdiri tahun 1998 di Pasuruan, Jawa Timur, Indonesia. PT ini memiliki sertifikasi kelayakan ekspor produk ikan beku ke Uni Eropa (UE) dengan nomor register (approval number) 234.13.B. Meski demikian, persentase produk tidak sesuai standar pada pengemasan meningkat dari $4.06 \%$ tahun 2012 menjadi $8.66 \%$ tahun 2013. Produk tidak standar ini perlu direprosesing dengan kemasan baru, sehingga menimbulkan pemborosan materi, waktu, dan menurunkan kualitas produk.

Menurut Watts et al. (1966) pengemasan vakum dan pendinginan dapat menurunkan kecerahan warna daging. Hal ini disebabkan sitokrom dalam daging dapat mereduksi metmioglobin kembali menjadi mioglobin. Warna daging merah terang terjadi bila daging terekspose udara, terjadi reaksi oksigenasi mioglobin membentuk oksimioglobin yang berwarna merah cerah.
Six Sigma mewakili tingkat kualitas dimana kesalahan paling banyak 3.4 cacat per 1 juta kemungkinan. Tingkat kualitas Six Sigma setara dengan variasi proses sejumlah setengah dari yang ditoleransi oleh tahap desain dan dalam waktu bersamaan memberi kesempatan agar ratarata produksi bergeser sebanyak 1,5 deviasi standar dari target (Evans dan Lindsay, 2007). Level Sigma diekspresikan dalam Defect per Million Opportunities (DPMO). DPMO mengindikasikan banyak kesalahan jika aktivitas diulang satu juta kali (Pande et al., 2009). Six Sigma terdiri dari tahap DMAIC (Define, Measure, Analyze, Improve, and Control) pengembangan dari siklus perbaikan PDCA (Plan-Do-Check-Act) (Srinivasan et al., 2014a; Srinivasan et al., 2014b).

Six Sigma telah diterapkan untuk perbaikan kualitas proses dan produk. Six Sigma sebagai perspektif penyelesaian masalah (de Mast and Lokkerbol, 2012), peningkatan presisi mesin dalam 
penggilingan (Nithyanandam and Pezhinkattil, 2014), peningkatan sistem manajemen pengetahuan (Lin, et al., 2013), peningkatan sharing informasi dalam rantai pasok (Mitchell and Kovach, 2016), dan peningkatan kualitas jamur kemasan (Sucipto, et al., 2017). Di sisi lain, penerapan Six Sigma untuk pengemasan vakum ikan beku belum dilakukan.

Penelitian ini bertujuan mengukur kapabilitas proses dengan pendekatan Six Sigma, sehingga teridentifikasi penyebab produk cacat saat pengemasan vakum ikan beku. Penelitian juga menggunakan metode Failure Modes and Effect Analysis (FMEA) sebagai dasar memberikan usul perbaikan.

\section{METODE}

Penelitian di PT X Pasuruan Jawa Timur Indonesia bulan Desember 2014 hingga Mei 2015. Bahan penelitian merupakan proses pengemasan ikan secara vakum, untuk diidentifikasi kecacatan proses pengemasannya. Data diolah di Laboratorium Manajemen Agroindustri Departemen Teknologi Industri Pertanian Fakultas Teknologi Pertanian Universitas Brawijaya. Penelitian ini menggunakan metode deskriptif kuantitatif, yang terdiri penyajian data, analisis, dan interpretasi data. Tahap penelitian sebagai berikut:

\section{Survei Lapang}

Survei lapang untuk memperoleh informasi dan mengetahui kondisi objek penelitian.

\section{Pengumpulan Data}

Data produk cacat (tidak sesuai standar) pada proses pengemasan vakum periode produksi Januari- Desember 2014.

\section{Pengolahan dan Analisa Data}

Tahap ini menggunakan metode Six Sigma yang dibatasi tahap Define, Measure, Analyze, dan Improve. Penjelasannya sebagai berikut.

\section{a. Tahap Define}

Tahap define untuk mengidentifikasi syarat kualitas kritis yang sering terjadi di perusahaan dengan diagram Pareto. Penetapan karakteristik kualitas atau Critical to Quality (CTQ) setelah diperoleh diagram Pareto terkait kebutuhan spesifik pelanggan dan kondisi perusahaan. CTQ merupakan kriteria kegagalan sehingga produk dinyatakan cacat atau tidak standar.

b. Tahap Measure

Langkah-langkah pada tahap ini sebagai berikut (Putri, 2010):

1. Pembuatan control chart $\mathrm{p}$

Diagram kontrol $\mathrm{p}$ digunakan bila data yang diamati adalah atribut dan perhitungannya berdasar proporsi cacat. Proporsi cacat suatu pengamatan merupakan perbandingan sampel cacat dengan jumlah sampel pengamatan (Trihendradi, 2008). Rumusnya sebagai berikut:

$$
\begin{aligned}
& \mathrm{UCL}=\bar{p}+6 \sqrt{\frac{\bar{p}(1-\bar{p})}{n}}(1) \\
& \mathrm{LCL}=\bar{p}-6 \sqrt{\frac{\bar{p}(1-\bar{p})}{n}}(2)
\end{aligned}
$$

Keterangan:

$\mathrm{p}^{-}=$garis pusat

$\mathrm{UCL}=$ Upper Control Limit

$\mathrm{LCL}=$ Lower Control Limit

2. Pengukuran kapabilitas proses untuk data atribut

Pengukuran ini meliputi:

a. Perhitungan Defect per Opportunities (DPO)

DPO adalah ukuran kegagalan yang menunjukkan jumlah cacat per satu kesempatan dengan rumus berikut:

$$
D P O=\frac{\text { cacat }}{\text { unit yang diproduksi } \times C T Q}
$$

b. Perhitungan Defect per Million Opportunities (DPMO)

DPMO merupakan pengertian kinerja kualitas sebagai tingkat kecacatan per satu juta kemungkinan dengan rumus berikut: 


\section{$D P M O=D P O \times 1000000$ \\ c. Perhitungan Sigma Level \\ Perhitungan Sigma Level menggunakan Microsoft Excel versi 2010:}

$=$ Normsinv $(1-\mathrm{DPMO} / 1000000)+\mathrm{SHIFT}$

Nilai shift adalah nilai pergeseran variansi yang akan mempengaruhi nilai atau level Sigma. Pergeseran nilai Sigma untuk level kualitas 5 Sigma adalah 0.5, untuk level kualitas 5.5 Sigma adalah 1, dan untuk level kualitas 6 Sigma sebesar 1.5 (Syukron dan Kholil, 2013). Karena penelitian ini menggunakan metode Six Sigma sehingga menggunakan nilai shift sebesar 1.5.

d. Kapabilitas Proses

Kapabilitas proses adalah kemampuan proses untuk memproduksi atau menyerahkan output sesuai ekspektasi dan kebutuhan pelanggan (Sugian, 2006). Kapabilitas proses diketahui dengan menghitung indeks kapabilitas proses $(\mathrm{Cp})$ dan final yield. Rumusnya adalah:

Final Yield $=100 \%-$

$\left(\left(\frac{\text { jumlah cacat }}{\text { jumlah inspeksi }}\right) \times 100 \%\right)$

Menurut Park (2006), hubungan nilai Sigma dan indeks kapabilitas proses $(\mathrm{Cp})$ adalah:

$$
\begin{aligned}
& \text { Nilai Sigma }=3 \times \text { Cp (7) } \\
& \text { c. Tahap Analyze }
\end{aligned}
$$

Tahap ini dilakukan dengan urutan sebagai berikut:

1. Pembuatan diagram cause and effect (C\&E) untuk mengumpulkan informasi hasil brainstorming penyebab masalah.

2. Pembuatan Failure Modes and Effect Analysis (FMEA) untuk mengidentifikasi dan menilai resiko yang terkait potensi kegagalan.

Tipe FMEA yang digunakan adalah Process FMEA. Process FMEA digunakan untuk menganalisis proses produksi dan perakitan sehingga focus pada modus kegagalan yang disebabkan proses produksi atau perakitan. Metode FMEA mengenal Risk Priority Number (RPN) yakni menggambarkan area yang dijadikan prioritas. RPN diukur berdasarkan rating dari 3 faktor, yakni severity, occurance, dan detection. Rumus RPN adalah sebagai berikut (Syukron dan Kholil, 2013):

RPN $=$ rating severity $x$ rating occurance $\mathrm{x}$ rating detection

d. Tahap Improve

Tahap ini dilakukan dengan menganalisis penyebab masalah utama berdasar hasil FMEA, kemudian merekomendasikan usulan perbaikan terhadap masalah cacat pada proses pengemasan.

\section{Pengambilan Keputusan dan Pemberian Saran}

Pengambilan keputusan berdasar hasil pengolahan dan analisis data penelitian. Hasil analisis perbaikan diajukan sebagai usulan peningkatan kualitas hasil proses pengemasan vakum ikan beku ke perusahaan.

\section{HASIL DAN PEMBAHASAN}

Pengendalian kualitas proses pengemasan vakum fillet ikan menggunakan metode Six Sigma meliputi tahap define, measure, analyze, dan improve.

\section{a. Tahap Define}

Tahap define memetakan jumlah produksi dan produk cacat pada pengemasan vakum ke diagram Pareto. Persentase cacat terlihat pada Gambar 1.

Menurut Evans dan Lindsay (2007) diagram Pareto menunjukkan masalah utama yang harus segera diselesaikan sehingga dapat memperbaiki proses tersebut. Diagram Pareto membantu analisis secara progresif berfokus pada masalah spesifik. Garis di atas diagram menunjukkan nilai kumulatif persentase penyimpangan mulai urutan terbesar hingga terkecil. Berdasar hal tersebut maka 
masalah utama (CTQ prioritas) yang harus diperbaiki adalah kemasan bocor.

Plastik pengemas menggunakan Polietilen Densitas Rendah (PEDR). Bahan ini bersifat kuat, agak tembus cahaya, fleksibel dan permukaannya agak berlemak. Daya proteksi terhadap uap air baik, tetapi kurang baik bagi gas-gas lain seperti oksigen. Titik lunak rendah, sehingga tidak tahan proses sterilisasi uap panas dan bila ada senyawa kimia bersifat polar akan mengalami stress cracking (retak oleh tekanan) (Sulchan dan Nur, 2007).

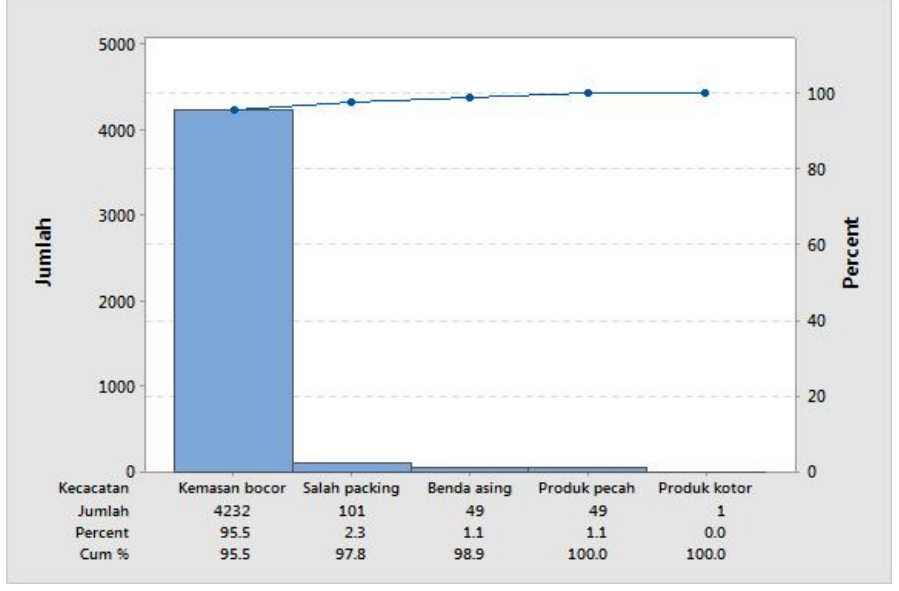

Gambar 1 Diagram Pareto penyimpangan pada proses pengemasan

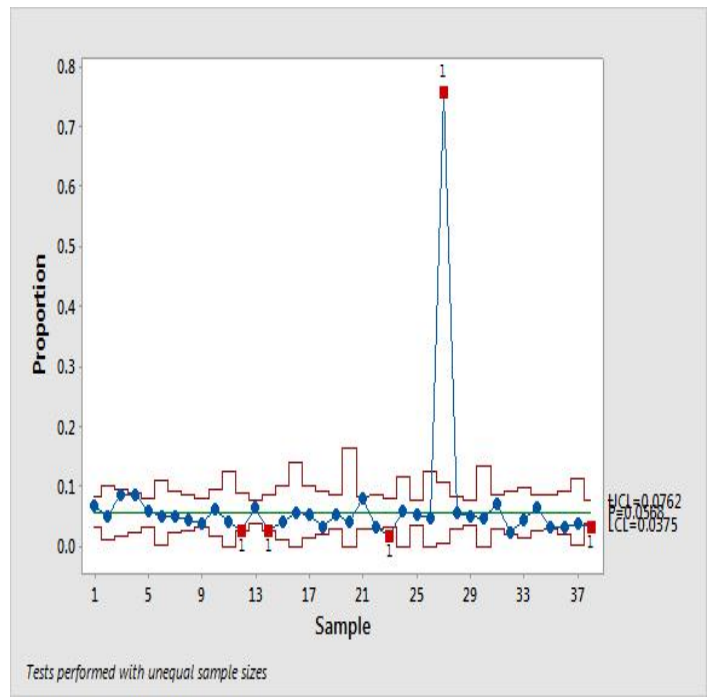

(a)

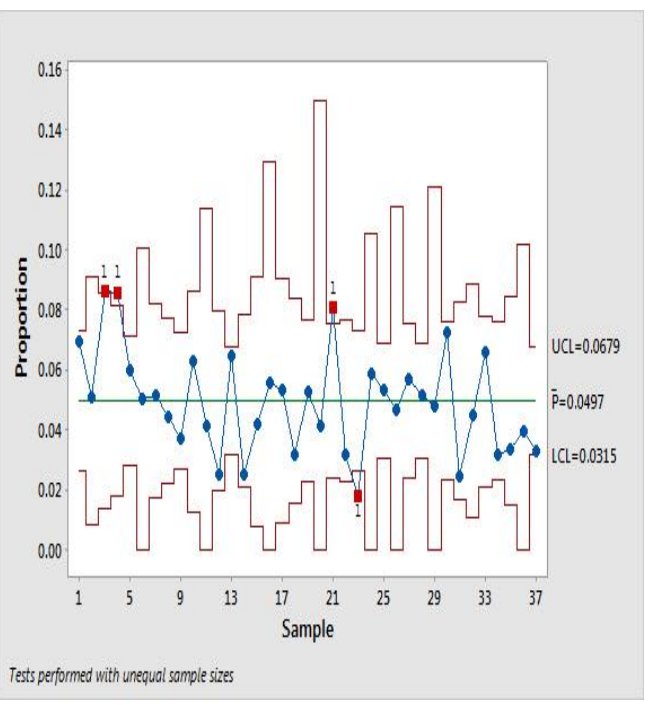

(b)

Gambar 2 Peta Kendali p (a) awal (b) revisi

\section{b. Tahap Measure}

Tahap ini merupakan tindak lanjut proses define yang ditunjang data pengukuran. Pembuatan peta kendali $p$ dan perhitungan kapabilitas proses untuk data atribut dilakukan pada tahap ini.
Peta kendali p pada Gambar 2. Nilai UCL dan LCL pada peta kendali $\mathrm{p}$ tidak sama untuk setiap sampel karena jumlah produk berbeda, sehingga data disesuaikan jumlah produk. Menurut Syukron dan Kholil (2013) perusahaan terkadang menggunakan pemeriksaan produk $100 \%$, biasanya banyak unit pemeriksaan menjadi 
tidak konstan. Grafik pengendali untuk sampel berbeda-beda biasa digunakan dalam keadaan ini, batas pengendali keduanya berubah sesuai ukuran sampel.

Beberapa titik LCL yang bernilai minus, saat pembuatan peta kendali dibuat menjadi nol. Menurut Kuswadi dan Mutiara (2004) bila nilai LCL negatif dianggap sama dengan 0 . Peta kendali ini memudahkan monitoring kinerja proses serta mendeteksi cepat kondisi di luar kendali. Menurut Evans dan Lindsay (2007) penyebab khusus dapat mempengaruhi kemampuan proses seperti tenaga kerja kurang terampil dan perlu perbaikan mesin. Pada Gambar 2a ada data menyimpang jauh pada titik ke 27 , maka dibuat peta kedali revisi dengan menghilangkan titik tersebut (Gambar 2b). Pada peta kendali p masih ada 4 titik di luar batas kendali.
Hasil pengambilan data primer untuk cacat pada kemasan bocor dibuat peta kendali $\mathrm{p}$ seperti Gambar 3. Semua titik berada dalam batas UCL dan LCL, artinya semua data diterima dan terkendali. Hal ini terjadi karena ada pengendalian (pengawasan) secara penuh saat observasi. Sigma melambangkan estimasi standar deviasi atau variasi proses. Semakin tinggi Sigma semakin rendah jumlah variasi (Bateman dan Snell, 2008). Nilai Sigma didapat dari konversi nilai DPMO. Hasil pengukuran kapabilitas proses pengemasan vakum pada Tabel 1. Nilai Sigma 3.06 - 3.34 tersebut masih di atas tingkat rata-rata industri di Indonesia dengan nilai Sigma 2.00. Hasil data primer lebih baik dibanding pengukuran sebelumnya karena saat penelitian kondisi produksi terkontrol (dalam pengawasan).

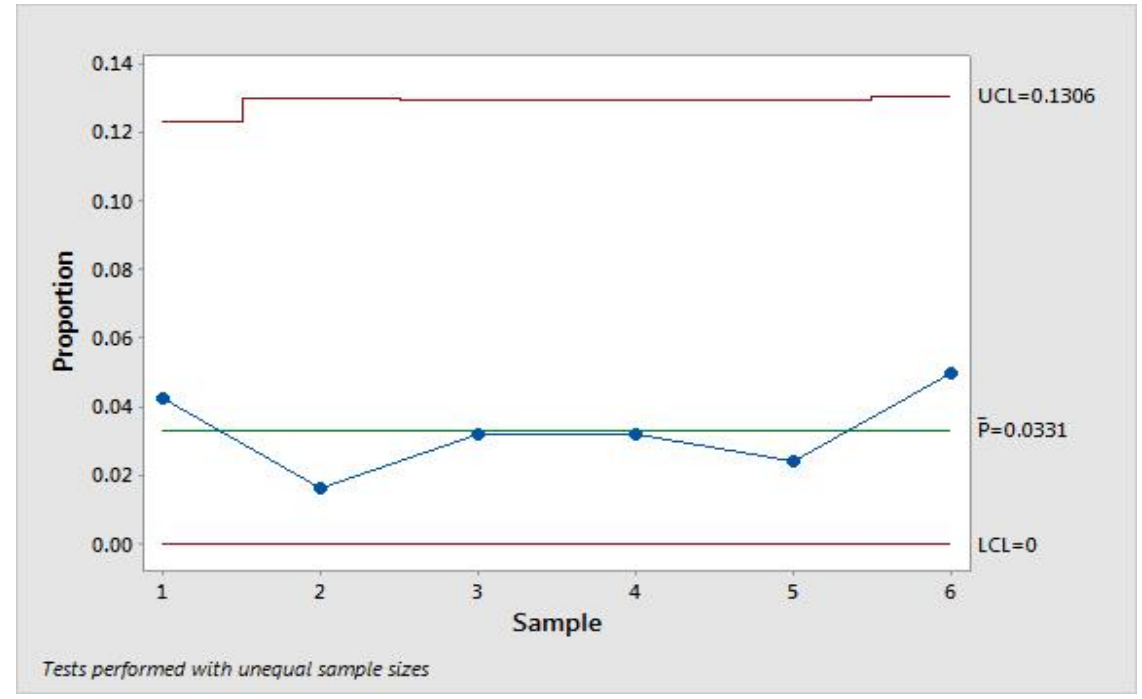

Gambar 3 Peta kendali $\mathrm{p}$ data primer

Tabel 1 Kapabilitas proses pengemasan vakum untuk data atribut

\begin{tabular}{|c|c|c|c|c|c|}
\hline \multirow[b]{2}{*}{ Langkah } & \multirow[b]{2}{*}{ Tindakan } & \multirow[b]{2}{*}{ Persamaan } & \multicolumn{3}{|c|}{ Hasil perhitungan } \\
\hline & & & $\begin{array}{c}\text { Data } \\
\text { historis }\end{array}$ & $\begin{array}{c}\text { Data } \\
\text { Revisi }\end{array}$ & $\begin{array}{c}\text { Data } \\
\text { primer }\end{array}$ \\
\hline 1 & Proses apa yang diketahui & - & \multicolumn{3}{|c|}{ Proses pengemasan } \\
\hline 2 & Banyak unit yang diperiksa & - & $\begin{array}{l}74,457 \\
\text { produk }\end{array}$ & $\begin{array}{l}73,708 \\
\text { produk }\end{array}$ & $\begin{array}{c}756 \\
\text { produk }\end{array}$ \\
\hline 3 & Banyak unit yang cacat & - & $\begin{array}{c}4,432 \\
\text { produk }\end{array}$ & $\begin{array}{c}3,863 \\
\text { produk }\end{array}$ & $\begin{array}{l}25 \\
\text { produk }\end{array}$ \\
\hline 4 & DPO & 3 & 0.0595 & 0.0524 & 0.0331 \\
\hline 5 & $\begin{array}{l}\text { Kemungkinan } \\
\text { penyimpangan per satu juta }\end{array}$ & 4 & 59,500 & 52,400 & 33,100 \\
\hline
\end{tabular}




\begin{tabular}{lllccc}
\hline & $\begin{array}{l}\text { kesempatan yang } \\
\text { dihasilkan proses (DPMO) }\end{array}$ & & & & \\
6 & Konversi DPMO ke dalam & 5 & 3.06 & 3.12 & 3.34 \\
& nilai Sigma & 6 & $94.05 \%$ & $94.76 \%$ & $96.69 \%$ \\
7 & Nilai final yield & 7 & 1.02 & 1.04 & 1.11 \\
\hline
\end{tabular}

Suatu proses dikatakan baik bila nilai final yield $\geq 99.73 \%$ untuk standar internasional dan $\geq 69.15 \%$ untuk standar Indonesia. Kemampuan proses di PT X sudah baik dengan nilai lebih dari standar Indonesia, tetapi perlu ditingkatkan agar sesuai standar internasional. Produk PT X sebagian besar diekspor sehingga seharusnya kemampuan prosesnya memenuhi standar internasional.

Penentuan kapabilitas berfungsi untuk mengukur kinerja suatu proses produksi serta mengetahui kelayakan proses dalam menghasilkan produk. Nilai indeks kapabilitas proses (Cp) menunjukkan produksi PT $\mathrm{X}$ tergolong memiliki kemampuan menengah (moderate capability). Tindakan yang harus diambil adalah pengendalian proses secara tegas, yakni mengawasi bagian produksi untuk mengurangi ketidaksesuaian dengan standar produk sehingga nilai Sigma dapat ditingkatkan.

\section{c. Tahap Analyze}

Tahap ini menganalisis semua masalah dan hasil pengukuran tahap sebelumnya. Diagram tulang ikan digunakan untuk mengidentifikasi semua penyebab seperti pada Gambar 4. FMEA untuk mengetahui penyebab potensial masalah (Ganguly, 2012). Ini adalah hasil dari sesi brainstorming dengan bagian terkai pengemasan di PT X.

Hasil pengamatan menunjukkan, faktor metode penyebab plastik bocor adalah cara pemindahan produk dari pan ke keranjang dan penempatan keranjang terlalu rendah dari conveyor.

Manusia berperan penting karena hampir seluruh proses pengemasan dikerjakan oleh tenaga kerja (manual). Tenaga kerja yang kurang hati-hati ketika memindahkan produk dapat menyebabkan produk terbentur benda kerja (keranjang) atau terjadi benturan antar produk. Tenaga kerja kurang memahami Good Manufacturing Practices (GMP). GMP merupakan praktik manufaktur yang baik dan persyaratan minimum untuk kebersihan dan pengolahan yang diperlukan untuk memastikan produksi secara aman. GMP banyak dijadikan standar prosedur perusahaan makanan dan farmasi (Sugian, 2006).

Metode FMEA dilakukan untuk membantu perencanaan perbaikan kualitas melalui identifikasi faktor-faktor kritis jenis kesalahan yang terjadi, kemudian menentukan tindakan koreksinya (Kholik, 2008). FMEA dalam penelitian ini dibuat berdasar hasil diagram tulang ikan pada Gambar 4. Hasil FMEA pada Tabel 2. Berdasar FMEA penyebab kemasan bocor adalah benturan antar produk sering terjadi saat pemindahan produk di peringkat 1 . Hal ini menunjukkan bahwa faktor manusia sangat penting, sehingga perlu kontrol berkala serta penerapan SOP karena SOP tidak selalu tersedia di tempat kerja. 


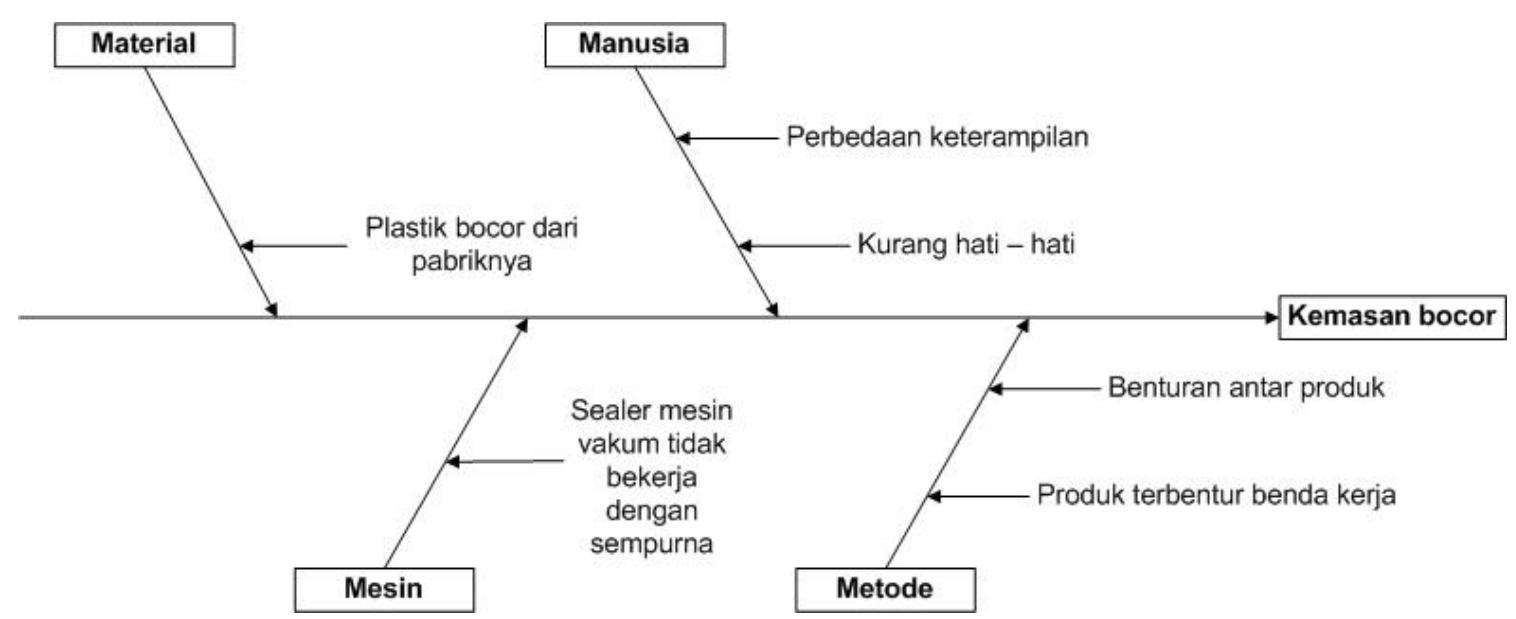

Gambar 4 Diagram sebab akibat kemasan bocor

Tabel 2 Failure Modes and Effect Analysis (FMEA) kemasan bocor

\begin{tabular}{clccccc}
\hline No & \multicolumn{1}{c}{$\begin{array}{c}\text { Penyebab } \\
\text { kegagalan }\end{array}$} & $\begin{array}{c}\text { Frekuensi } \\
\text { kejadian }\end{array}$ & $\begin{array}{c}\text { Tingkat } \\
\text { keparahan }\end{array}$ & $\begin{array}{c}\text { Perkiraan } \\
\text { deteksi }\end{array}$ & RPN & Peringkat \\
\hline 1 & $\begin{array}{l}\text { Produk terbentur } \\
\text { benda kerja }\end{array}$ & 7 & 8 & 6 & 336 & 2 \\
2 & $\begin{array}{l}\text { Sealer mesin } \\
\text { vakum tidak } \\
\text { bekerja sempurna }\end{array}$ & 3 & 6 & 4 & 72 & 3 \\
3 & $\begin{array}{l}\text { Plastik bocor dari } \\
\text { pabrik }\end{array}$ & 1 & 6 & 1 & 6 & 4 \\
4 & $\begin{array}{l}\text { Benturan antar } \\
\text { produk }\end{array}$ & 8 & 9 & 8 & 576 & 1 \\
\hline
\end{tabular}

\section{d. Tahap Improve}

Pada tahap improve dirancang usulan perbaikan hasil analisis FMEA (Tabel 2) dan diagram tulang ikan (Gambar 4). Kesalahan pengemasan terbanyak adalah tenaga kerja. Arahan pengawas diperlukan supaya pekerja bekerja lebih teliti dan menghindari kesalahan. Menurut Arifin dan Fauzi (2007) pengarahan semua tenaga kerja agar bekerja sama dan bekerja efektif serta efisien untuk mencapai tujuan perusahaan. Hasil riset menunjukkan ketika pengawasan lebih baik menyebabkan DPMO menurun dari 52,000 menjadi 33,100, nilai Sigma, final yield, dan indeks kapabilitas proses meningkat (Tabel 1).

Tenaga kerja yang kurang memahami atau kurang menaati GMP pada proses pengemasan di PT X perlu diberi training agar mengerti dan tidak mengulangi kesalahan. Menurut Hardjana (2001) pelatihan dirancang untuk meningkatkan kinerja. Pelatihan sistematis, sesuai prosedur, dengan metode baku sesuai kebutuhan, sungguh-sungguh dan teratur terbukti dapat meningkatkan produktivitas kerja, kepercayaan diri, dan semangat kerja. Pelatihan tenaga kerja di PT X dapat dilakukan di perusahaan menggunakan contoh prosedur proses pengemasan vakum yang benar dan terstandar. Selanjutnya, perlu pengawasan sebagai evaluasi kinerja karyawan setelah pelatihan. Pelatihan untuk meningkatkan kesadaran tenaga kerja terhadap mutu dan produktivitas juga diperlukan. Menurut BBPP (2015) pelatihan ini bertujuan menumbuhkan dan meningkatkan 
kesadaran, pemahaman, dan partisipasi karyawan dalam meningkatkan mutu dan produktivitas sehingga dapat dibangun motivasi dan budaya produktif di perusahaan. Pelatihan akan membuat setiap karyawan bertanggung jawab terhadap mutu dan kualitas barang atau jasa.

PT X memberlakukan GMP dari Kementerian Kelautan dan Perikanan Direktorat Jenderal Pengolahan dan Pemasaran Hasil Perikanan. GMP ini berlaku 2 tahun. Menurut Madura (2007) team leader (pengawas) harus memantau agar tenaga kerja selalu bekerja sesuai instruksi kerja. Pengawasan di PT X perlu lebih ditingkatkan dan terjadwal secara periodik. Kegiatan ini dapat dilakukan 2 minggu atau 1 bulan sekali. Hasil monitoring diharapkan dapat menjadi umpan balik perbaikan GMP agar lebih rinci dan mudah diterapkan.

\section{KESIMPULAN}

Berdasar hasil penelitian disimpulkan bahwa pengawasan produksi sangat penting. Dengan pengawasan nilai Sigma 3.06 meningkat menjadi 3.12. Data primer menghasilkan Sigma 3.34. Nilai final yield sebesar $94.05 \%$ meningkat menjadi 94.76\% dengan indeks kapabilitas proses (Cp) 1.02 meningkat menjadi 1.04. Nilai final yield data primer sebesar $96.69 \%$ dengan nilai $\mathrm{Cp}$ sebesar 1.11 termasuk moderate capability. Nilai Sigma dan final yield PT $X$ di atas rata-rata industri Indonesia, tetapi masih di bawah rata-rata industri dunia.

Berdasar metode FMEA, masalah utama di PT X adalah benturan antar produk dengan nilai RPN 576 dan produk terbentur benda kerja dengan nilai RPN 336. Dua masalah tersebut disebabkan faktor manusia. Perbaikan dapat dilakukan dengan pengawasan lebih ketat, trainning, dan pengarahan tenaga kerja.

\section{DAFTAR PUSTAKA}

Arifin J dan Fauzi A. 2007. Aplikasi Excel dalam Aspek Kuantitatif Manajemen Sumber Daya Manusia. PT Elex Media Komputindo. Jakarta.

Bateman TS dan Snell SA. 2008. Manajemen Edisi 7. Salemba Empat. Jakarta.

BBPP. 2015. Pelatihan Manajeman Produktivitas. Dilihat pada 06 September 2015. http://www.bbpproduktivitas.org/index.php/layanan /pelatihan-manajemen-produktivitas.

de Mast J and Lokkerbol J. 2012. An analysis of the Six Sigma DMAIC method from the perspective of problem solving. Int. J. Production Economic, 139: 604-614.

Evans JR dan Lindsay WM. 2007. Pengantar Six Sigma. Salemba Empat. Jakarta.

Ganguly K. 2012. Improvement Process for Rolling Mill through The DMAIC Six Sigma Approach. International Journal for Quality research, 6(3): 221-231.

Hardjana AM. 2001. Training SDM yang Efektif. Kanisius. Yogyakarta

Kholik, H. 2008. Aplikasi DMAIC dalam metode Six Sigma dan eksperimen Shainin Bhote sebagai penurunan presentasi cacat. Jurnal Teknik Industri, 9(1): 117-127.

Kuswadi dan Mutiara E. 2004. Delta: Delapan Langkah dan Tujuh Alat Statistik untuk Peningkatan Mutu Berbasis Komputer. PT Elex Media Komputindo. Jakarta.

Lin C J, Chen F F, Wan H, Chen Y M, Kuriger G. 2013. Continuous Improvement of Knowledge ManagementSystems Using Six Sigma Methodology. Robotics and Computer-Integrated Manufacturing, 29(3): 95-103.

Madura J. 2007. Pengantar Bisnis Edisi 4. Salemba Empat. Jakarta. 
Mitchell E M, Kovach J V. 2016. Improving supply chain information sharing using Design for Six Sigma. European Research on Management and Business Economics, 22, 147154.

Nithyanandam G K and Pezhinkattil R. 2014. A Six Sigma approach for precission machining in milling. Procedia Engineering, 97: 17551764.

Pande PS, Neuman RP, dan Cavanagh RR. 2009. The Six Sigma Way. Penerbit ANDI. Yogyakarta.

Park SH. 2006. Six Sigma for Qulity and Productivity Promotion. The Asian Productivity Organization. Tokyo.

Putri CF. 2010. Upaya Menurunkan Jumlah Cacat Produk Shuttlecock dengan Metode Six Sigma. Widya Teknika, 18(2): 14-23.

Srinivasan K, Muthu S, Devadasan SR, and Sugumaran C. 2014a. Enhancing effectiveness of Shell and Tube Heat Exchanger through Six Sigma DMAIC Phases. Procedia Engineering, 97, 2064-2071.

Srinivasan K, Muthu S, Prasad N K, Satheesh G. 2014b. Reduction of paint line defects in shock absorber through Six Sigma DMAIC phases. Procedia Engineering, 97, 17551764.

Sucipto S, Sulistyowati D P, Aggrarini S. 2017. Pengendalian Kualitas Pengalengan Jamur dengan Metode Six Sigma di PT Y, Pasuruan, Jawa Timur. Industria: Jurnal Teknologi dan Manajemen Agroindustri, 6(1): $1-7$.

Sugian S. 2006. Kamus Manajemen (Mutu). PT Gramedia Pustaka Utama. Jakarta.

Sulchan M dan Nur E. 2007. Keamanan Pangan Kemasan Plastik dan Styrofoam. Maj Kedokt Indon, 57(2): 54-59.

Syukron A dan Kholil M. 2013. Six Sigma: Quality for Business Improvement. Graha Ilmu. Yogyakarta.

Trihendradi C. 2008. Statistik Six Sigma dengan Minitab. Penerbit ANDI. Yogyakarta.

Watts BM, J Kendrick, M Zipster, B Autchins and Saleh. 1966. Enzymatic Reducing Pathway in Meat. J. Food Sci., 31: 855-864. 